\title{
A Study on High School Students' Self-Concept Clarity, Stress and Interpersonal Relationships Affect Subjective Oral Health
}

\author{
Hye-Jung Jin ${ }^{1}$, Man Kyu $\mathrm{Huh}^{2}$, Min-Kyung Lee ${ }^{3}$ \\ ${ }^{1}$ Assistant Professor, Department of Dental Hygiene, Yeungnam University College, Republic of Korea \\ ${ }^{2}$ Professor, Department of Molecular Biology, Dong-Eui University, Republic of Korea \\ ${ }^{3}$ Assistant Professor, Department of Dental Hygiene, Dong-Eui University, Republic of Korea
}

\begin{abstract}
The present study was conducted in order to provide basic data that increases preventive oral health management behaviors by researching and analyzing the effect of high school students' self-identity, stress and interpersonal relationships on subjective oral health, and, consequently, the results are as follows. First, oral health appeared better when the self-identity of students was higher. Second, the degree of practicing oral health was higher when interpersonal relationships were better. Third, food intake habits related to oral health were better when stress was lowers and smoking behaviors were better. Fourth, subjective oral health was higher when students had good interpersonal relationships and did not smoke. The results of the present study may help the development of data and programs concerned with factors influencing the subjective oral health of high school students, but is considered too limited to be generalized.
\end{abstract}

Keywords: Self-Concept Clarity, Stress, Interpersonal Relationships, Subjective Oral Health

\section{Introduction}

The period between childhood and young adulthood is a period of rapid change - physical, emotional, cognitive and social. During this time, children's bodies change in different ways at different times. No two teenage bodies are the same. Boys and girls who develop very early or very late might feel more self-conscious and they get teased and have body image concerns. As an unstable period between childhood and adulthood, in which social order, institutions, and ideologies are yet to be established, adolescence involves both physical and mental changes, and adolescents, during this period, tend to be usually healthy and have a low oral disease prevalence ${ }^{1}$. However, the oral management habits cultivated at this time have an influential in adulthood, so adolescents must learn the proper oral management habits via proper knowledge and attitude regarding oral health in order to achieve a health oral environment. Various experiences, during this period, namely, curiosity toward the other sex and various psychological impulses cause moods swings to appear in the form of rebellion. Thus, this period requires interest from parents and the people around adolescents and understanding toward them. Hence, their oral environment must be healthily managed and awareness, attitude, and behavior toward oral health must be changed so that adolescents themselves have the ability to effectively and healthily manage their oral environment. Self-concept clarity, as a more detailed aspect of the self-concept, refers to how clearly and firmly individuals are defined and how a stable self-concept is formed with internal consistency ${ }^{2}$. A selfconcept refers to the attitudes and emotions of individuals toward themselves and includes individual attitudes, feelings, perceptions and self-assessments as an object.

An interpersonal relationship refers to a mutual contact between two or more people, and is defined as the universal psychological orientation of individuals toward people involving 'how you think and feel toward others and how you respond to the behavior of others ${ }^{3}$. Subjective well-being is a concept that includes the satisfaction felt in one's life and the emotion of happiness. It refers to an overall assessment of all aspects of life from a purely subjective viewpoint by which an individual thinks and makes judgements regardless of the objective conditions of happiness.

Stress is rising as an important issue related to health in a modern society which is increasingly complicated and departmentalized. The stimulus of an adequate amount of stress takes the role of optimistically accelerating individual lives but inadequate stress stimuli can harm the mental and physical health of individuals. Recently thoughts regarding adolescent stress has focused on how adolescents respond to stress rather than what kind of stress they experience. This phenomenon results from the possibility of reducing stress by the way one responds to stress elements. More than half a million South Korean students in their final year of high school recently took the university entrance examination. Many people consider success on this test the first step toward a good life. But South Korean students say they feel stressed from the pressure. The present study investigates oral environment management habits, oral health knowledge levels and subjective oral health status with high school students at the Daegu and Gyeongsangbuk-do regions as subjects and analyzes the effect of high school students' self-concept clarity, stress, and interpersonal relationships on subjective oral health, with the expectation of contributing to the increased oral health of high school students. 


\subsection{Research Subjects}

\section{Methods}

To conduct this study, we selected 1st, 2nd, 3rd grade students at high schools in the Daegu and Gyeongsangbuk-do regions. A survey method was used on a total of 462 subjects including 961 st grade students, 262 2nd grade students, and 84 3rd grade students, with the resulting data used for the study. The response results of 442 subjects were used in the final analysis excluding 20 surveys that were improperly understood or insincerely answered.

\subsection{Research tools}

\subsubsection{Self-Concept Clarity Scale}

The study modified and used Yang ${ }^{4}$ scale in order to evaluate self-concept clarity, internal consistency, and stability. Each question is marked using a five point scale from 'none what so ever (1 point)' to 'extremely so (5 points)'. 1-12 are marked inversely, and a higher score reveals the degree of how certain the subject knows oneself, the internal consistency between disciplines of self-knowledge and the temporal stability of selfknowledge, which refer to a high level of self-concept clarity. The internal reliability of the questions of the selfconcept scale conducted in the study is 0.762 .

\subsubsection{Stress Scale}

The stress scale used in the present study was developed by $\mathrm{Lee}^{5}$ and modified by Kim and $\mathrm{Kim}^{6}$. Factors stressing adolescents were divided into the five categories including school, home, interpersonal relationships, the self-domain, and the environmental domain, but the environmental domain was excluded, resulting in the remaining four categories. The data was arranged using the 1-5 point Likert scale, with a total of 23 questions. A higher total stress score means that the subject is under more stress. The internal consistency (Cronbach's $\alpha$ ), used in the study, regarding adolescent stress factors and experiences had a favorable reliability with a score of 0.895 .

\subsubsection{Interpersonal Relationship Scale}

The interpersonal relationship test is divided into 7 subcategories, which are satisfaction, communication, trust, friendliness, sensitivity, openness, and understanding. The data was arranged using 1-5 point Likert scale, and a higher total score meant that the subject's interpersonal relationships were amicable. The internal consistency (Cronbach's $\alpha$ ) of the interpersonal relationship scale used in the study had a favorable reliability with a score of 0.925 .

\subsubsection{Subjective Well-Being}

The subjective well-being scale consisted of a positive and negative emotion scale and life satisfaction. The positive and negative emotion scale used the measurement tool used by Heo ${ }^{7}$. When the subject perceived a high level of satisfaction in one's life, subjective well-being was high, and internal consistency had a favorable reliability with a score of 0.814 .

\subsection{Data Analysis}

Statistical analysis of changes in behavioral date was carried out with one-way analysis of the variance $(\mathrm{ANOVA})^{8}$. In all statistical comparisons, $p<0.05$ was used as the criterion for statistical significance. All data is represented as mean \pm standard error.

\section{Results}

The frequency analysis results of the general characters of research subjects are indicated in Table 1. Parents' academic background components also largely contribute to the home environment that they provide for their children.

Table 1: General characteristics of research subjects

\begin{tabular}{|l|l|l|l|}
\hline Categories & $\mathrm{N}$ & $\%$ \\
\hline \multirow{3}{*}{ Gender } & Male & 258 & 58.4 \\
\cline { 2 - 4 } & Female & 184 & 41.6 \\
\hline \multirow{3}{*}{ Grade } & 1st grade & 96 & 21.7 \\
\cline { 2 - 4 } & 2nd grade & 262 & 59.3 \\
\cline { 2 - 4 } & 3rd grade & 84 & 19.0 \\
\hline
\end{tabular}




\begin{tabular}{|l|l|l|l|}
\hline \multirow{2}{*}{$\begin{array}{l}\text { Father' } \\
\text { background }\end{array}$} & $\begin{array}{l}\text { High school graduate or } \\
\text { below }\end{array}$ & 85 & 19.2 \\
\cline { 2 - 4 } & $\begin{array}{l}\text { College graduate or } \\
\text { above }\end{array}$ & 357 & 80.8 \\
\hline \multirow{2}{*}{$\begin{array}{l}\text { Mother' } \\
\text { background }\end{array}$} & $\begin{array}{l}\text { High school graduate or } \\
\text { below }\end{array}$ & 125 & 28.3 \\
\cline { 2 - 5 } School grades & $\begin{array}{l}\text { College graduate or } \\
\text { above }\end{array}$ & 317 & 71.7 \\
\hline & Top & 204 & 46.2 \\
\cline { 2 - 5 } & Middle & 138 & 31.2 \\
\cline { 2 - 5 } & Bottom & 100 & 22.6 \\
\hline Overall & & 442 & 100.0 \\
\hline
\end{tabular}

In order to find out the average and standard deviation of the high school students' self-concept clarity, stress, interpersonal relationships, and subjective well-being, the study conducted frequency analysis and calculated percentages. The results are indicated by Table 2. A comparison between the perfect score of each scale and the average score of the students' shows that the perfect score of self-concept clarity at 60.00 and the average of self-concept clarity at 7.53. At a perfect stress scale score of 115.00 , the stress average of students was 52.88 , and, at a perfect interpersonal relationships score of 125.00 , the average interpersonal relationships score of students was 69.42 .

Table 2: The level of high school student self-concept clarity, stress, interpersonal relationships, and subjective well-being

\begin{tabular}{|l|l|l|l|l|l|}
\hline Variables & Average & $\begin{array}{l}\text { Standard } \\
\text { Deviation }\end{array}$ & Minimum & Maximum & $\begin{array}{l}\text { Perfect } \\
\text { Score }\end{array}$ \\
\hline Self-clarity & 31.58 & 7.53 & 12.00 & 56.00 & 60.00 \\
\hline Stress & 52.88 & 14.43 & 23.00 & 86.00 & 115.00 \\
\hline Interpersonal relationships & 89.42 & 13.96 & 25.00 & 125.00 & 125.00 \\
\hline
\end{tabular}

Subjective oral health awareness is indicated by Table 3. The 191 (43.2\%) subjects responded with the highest ranking response of 'normal' in terms of subjective oral interest, while 196 (44.3\%) responded with the highest ranking response of 'normal' in terms of subjective oral health condition, followed by 'healthy' with 134 responses (30.3\%). In terms of subjective health problems, dental caries was the highest response at $76(17.2 \%)$ followed by the aesthetic aspect at $27(6.1 \%)$, bad breath at $21(4.8 \%)$, periodontal disease at $19(4.3 \%)$, and miscellaneous at $16(3.6 \%)$. In terms of cavity treatment experience, the most common response was 'I don't know' at $139(31.4 \%)$.

Table 3: The estimates of subjective oral health awareness

\begin{tabular}{|c|c|c|c|}
\hline Subject & Item & $\mathrm{N}$ & $\%$ \\
\hline \multirow[t]{5}{*}{ Subjective oral interest } & Very interested & 31 & 7.0 \\
\hline & Relatively interested & 140 & 31.7 \\
\hline & Normal & 191 & 43.2 \\
\hline & Not interested & 67 & 15.2 \\
\hline & Totally uninterested. & 13 & 2.9 \\
\hline \multirow[t]{5}{*}{ Subjective oral health } & Very healthy & 33 & 7.5 \\
\hline & Healthy & 134 & 30.3 \\
\hline & Normal & 196 & 44.3 \\
\hline & Unhealthy & 71 & 16.1 \\
\hline & Very unhealthy & 8 & 1.8 \\
\hline \multirow[t]{5}{*}{ Subjective health issues } & Dental caries & 76 & 17.2 \\
\hline & Periodontal disease & 19 & 4.3 \\
\hline & Aesthetic aspect & 27 & 6.1 \\
\hline & Bad breath & 21 & 4.8 \\
\hline & Miscellaneous* & 16 & 3.6 \\
\hline \multirow[t]{5}{*}{ Cavity treatment experience } & None & 76 & 17.2 \\
\hline & 1 & 39 & 8.8 \\
\hline & 2 & 49 & 11.1 \\
\hline & 3 & 39 & 8.8 \\
\hline & 4 & 100 & 22.6 \\
\hline
\end{tabular}




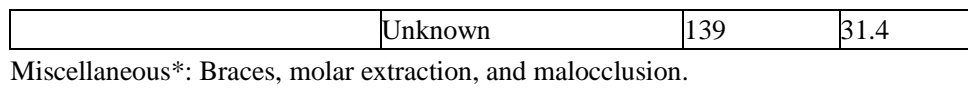

The study conducted correlation analysis in order to find out the relationship between sub variables including self-identity, stress, school life, and subjective oral health, and the results are indicated by Table 4. The subjective well-being of self-identity had a negative (-) relationship with self-concept clarity $(r=-0.190, p$ $<0.001)$ and stress $(r=-0.398, p<0.001)$, and a positive $(+)$ relationship with interpersonal relationships $(r=$ $0.534, p<0.001)$ and oral health status $(r=0.161, p<0.01)$. Self-concepts had a positive $(+)$ relationship with stress $(r=0.427, p<0.001)$ and a negative $(-)$ relationship with interpersonal relationships $(r=-0.234, p<$ $0.001)$ and oral health status $(r=-0.185, p<0.001)$. Stress only had negative $(-)$ relationships. Interpersonal relationships in school life had a positive $(+)$ relationship with oral health status $(r=0.169, p<0.001)$.

Table 4: Correlation between sub-variables

\begin{tabular}{|c|c|c|c|c|c|c|}
\hline \multirow{2}{*}{\multicolumn{2}{|c|}{ Variable }} & \multicolumn{2}{|l|}{ Self-identity } & \multirow[b]{2}{*}{ Stress } & \multirow{2}{*}{\begin{tabular}{|l} 
School life \\
$\begin{array}{l}\text { Interpersonal } \\
\text { relationships }\end{array}$
\end{tabular}} & \multirow{2}{*}{\begin{tabular}{|l|}
$\begin{array}{l}\text { Subjective } \\
\text { oral health }\end{array}$ \\
$\begin{array}{l}\text { Oral health } \\
\text { status }\end{array}$
\end{tabular}} \\
\hline & & $\begin{array}{l}\text { Subjective well- } \\
\text { being }\end{array}$ & $\begin{array}{l}\text { Self- } \\
\text { concept } \\
\text { clarity }\end{array}$ & & & \\
\hline \multirow{2}{*}{ Self-identity } & Subjective well-being & 1 & & & & \\
\hline & Self-concept clarity & $-.190^{\text {**** }}$ & 1 & & & \\
\hline \multicolumn{2}{|l|}{ Stress } & $-.398^{\text {**** }}$ & $.427^{* * * *}$ & 1 & & \\
\hline School life & Interpersonal relationships & $.534^{* k * k}$ & $-.234^{* * * *}$ & $-.440^{* * 0 k}$ & 1 & \\
\hline $\begin{array}{l}\text { Subjective } \\
\text { oral health }\end{array}$ & Oral health conditions & $.161^{* *}$ & $-.185^{* * *}$ & $-.201^{\text {*epk }}$ & $.169^{* * * k}$ & 1 \\
\hline
\end{tabular}

\section{DISCUSSION}

Adolescent on the other hand is defined by World Health Organization (WHO) as a person between the ages of 10-19 years; while adolescence period is a period of transition from childhood to adulthood. Many changes occur both physically and mentally during adolescence which is the middle stage between childhood and adulthood. According to Sunmola ${ }^{9}$, the transition is characterized by an increase in personal control, responsibilities and independence. This adolescent period is when changes in oral health beliefs are capable, and thus, it is reported that subjects maintain a sound oral health condition along with the increase in age when they have proper beliefs regarding oral health during this period ${ }^{1}$. A study by Lee et al. ${ }^{10}$ revealed that 56.5 percent of Korean adolescents experience stress due to academic related concerns. The authors suggested that academicrelated stressors turn into significant mental health concerns. Also, most of the stress occurring in daily life causes physical and mental disease, and the response of the body toward stress causes pathological phenomena within each individual so as to react as an important factor that aggravates symptoms or causes various diseases. Adolescence is a period when mental growth like self-consciousness and cognitive ability and physical growth like secondary sexual characteristics rapidly occur and subjects may experience severe mental conflicts more than any other time period. In particular, adolescence directly affects the oral health status of adulthood so much effort must be exerted toward oral health management. In the present study, the high burden of morbidities may be attributed to negligence and lack of availability of health services to the children and adolescents. Therefore, the present study aims at finding out how the self-concept clarity, stress and school life of high school students affects subjective oral health status by targeting high school students in the Daegu and Gyeongsangbuk-do regions. It is the fit between an early adolescent's family environment and his or her developmental needs that is critical to successful adaptation by both parents and early adolescents in this transitional period ${ }^{11}$. The main results of the study are as follows.

1) The analysis on the effect of self-concept clarity, stress, and school life on subjective oral health revealed that stress $(r=-0.122, p<0.05)$ had a negative $(-)$ effect on subjective oral health, and that school life $(r=0.227, \mathrm{p}<.001)$ had a positive effect $(+)$. In other words, subjective oral health status was higher when stress was lower and school life was better.

2) Analysis on the effect of self-concept clarity, stress, and school life on oral health status revealed that self-concept clarity had a negative effect on oral health status. In other words, oral health status was better when self-concept clarity was lower. These research results will aid the development of data and programs related to the factors influencing the subjective oral health of high school students, but because the location is limited to certain areas and the students engaged in an insincere attitude toward filling out the surveys, it is difficult to generalize them. Therefore, follow-up studies should expand the research area of the subjects and draw out the participation of the students so that the analysis and research becomes more in-depth. 


\section{References}

[1]. H.J. Noh, C.H. Choi, W. Sohn, The relationship between oral health behavior and frequency of oral health education in adolescent, Journal of the Korean academy of dental health, 2008, 32: 203-213.

[2]. J.D. Campbell, Self-esteem and clarity of the self-concept, Journal of Personality and Social Psychology, 1990, 59: 539-549.

[3]. F. Heider, Attitudes and cognitive organization, Journal of Social and Clinical Psychology, 1946, 21: $107-111$.

[4]. M.H. Yang, E.J. Kim, The empirical study on the adolescents' anger - its relationship to self-concept clarity and personality traits, Studies on Korean Youth, 2007, 18: 163-184.

[5]. J.S. Lee, A study on the stress factors and coping activities of high school students, Master's thesis, Youngnam University, Daegu, 1988.

[6]. E. Kim, J. Kim, The mediating effects of academic failure tolerance on the relationships between irrational beliefs, perceived parents' achievement pressure and the school adjustment of middle school students, Studies on Korean Youth, 2013, 24: 119-148.

[7]. J.H. Heo, Effects of the frequency of the experience of positive emotions on the adolescents' subjective well-being, Korean Journal of Counseling, 2012, 13: 31-46.

[8]. J.H. Zar, Biostatistical Analysis, Prentice-Hall Inc., 1984, pp. 718, Englewood Cliffs, New Jersey.

[9]. F.T. Sunmola, Optimizing Learning with Transferable Prior Information, Doctor's thesis, University of Birmingham

[10]. Birmingham United Kingdom, 2012.

[11]. J. Lee, A. Puig, Y. Kim, H. Shin, J.H. Lee, S.M. Lee, Academic burnout profiles in Korean adolescents. Stress and Health, 2010, 26(5): 404-416.

[12]. J.S. Eccles, C. Midgley, A. Wigfield, et al., Development during adolescence: the impact of stage-environment fit on adolescents' experiences in schools and families, American Psychologist, 1993, 48: 90-101. 